\title{
Malaria in Bulambya, Ileje district, south-west Tanzania
}

\author{
B.T.A. MAEGGA ${ }^{1 *}$, A. K. KALINGA ${ }^{1}$, S.W. CHACHA ${ }^{2}$, M. KIBONA ${ }^{1}$, J. MWAYAWALE ${ }^{2}$ \\ \& K. JANGSON ${ }^{2}$ \\ ${ }^{1}$ National Institute for Medical Research, Tukuyu Research Station, \\ P.O Box 538, Tukuyu, Tanzania \\ ${ }^{2}$ Ileje District Council, District Medical Office, P.O Box 2, Itumba, Tanzania
}

\begin{abstract}
This study was carried out to determine malaria situation in Bulambya Division, Ileje district in southwest Tanzania. Outpatient attendance records from 1999 to 2002 were examined for malaria cases in eleven health facilities. A cross-sectional study to determine malaria prevalence and its potential vectors was done in May 2004. Blood samples were collected from 502 schoolchildren from 16 primary schools and examined microscopically for malaria parasites. Indoor resting mosquitoes were collected in ten houses in each of the ten villages covered. Health facility data for 1999 showed the highest (60.7\%) and lowest (11.5\%) annual malaria morbidity rates were recorded at Itumba and at Ibaba, respectively. Malaria parasitaemia rate among schoolchildren ranged from 0-36.7\%; the lowest prevalence was observed in the high altitude mountainous range and the highest in the lower altitude plateaux. Of 1,504 mosquitoes caught, 205 (13.6\%) were female Anopheles gambiae s.l., 215 (14.3\%) An. funestus and 68.9\% were culicines. Data from both health facility records and school surveys indicate that there is high malaria morbidity in the lower plateaux (1100 to $=1350 \mathrm{~m})$, around Itumba and Isongole, where indoor anopheles mosquito densities were relatively higher than in the higher altitudes $(>1,350 \mathrm{~m})$ around Ibaba. In the lower altitude range, there was less malaria on steep slopes than on flat terrain. Further studies are recommended to closely monitor malaria situation in these epidemic prone highlands of southwest Tanzania.
\end{abstract}

\section{Introduction}

Malaria is one of the commonest communicable diseases that cause much sufferings and deaths in warm tropical countries because of the ecology, which supports rapid vector population multiplication and short parasite development cycle in the mosquito vectors. In Sub-Saharan Africa, this disease has devastating impact on socio-economic development, as it perpetuates poverty and enhances underdevelopment. Globally, about 550 million people are at risk of contracting malaria with an annual total of between 250-450 million clinical cases reported, and an estimate of over one million deaths (WHO, 1993). Malaria is responsible for about $10 \%$ of hospital admissions and 20-30\% outpatient consultations (WHO, 1993). In Tanzania, the disease occurs throughout the country, and ranks high in the top ten causes of morbidity and mortality. There is intense transmission in a large portion of the country, with few small "islands of low or no transmission", due to ecological and climatic factors (Clyde, 1967).

Mbeya region in the southwestern highlands of Tanzania was once considered malaria free on the basis of its topography (Clyde, 1967). However, since this data was published, most areas in the region have gradually been modified ecologically, such that the numbers of cases of clinical malaria have increased (Maegga et al., 2005). For instance, Clyde (1967) recorded malaria parasite prevalence of $15 \%$ in Rungwe-Kyela area. This area covers a wide range of altitudes, from just about 500m, around Kyela flood plains to over 3,000m on the Mporoto Mountains and mounts Rungwe and Kyejo volcanic summits.

The unit record of $15 \%$ prevalence probably represented some intermediate altitude, and is unlikely to represent such a wide span of vector and disease ecological range. In a study carried out 15 years later (Minja \& Matola (1982), the Kyela lowlands were found to have an overall parasite rate of $44.7 \%$. However, their study site was likely to have different vector ecology compared to the rest of Mbeya region, mostly comprised of high ridges punctuated by deep valleys, and mountain peaks. Kyela being located in the bottom of the Rift Valley area just north of Lake Nyasa is unlikely to represent the highlands that make a larger portion of Mbeya region. In the latter part, no recent malaria status data exists, except for few facility based records, which at best, are regarded as just a sign of the existence of the problem and not a measure of its magnitude (Maegga et al., 2005).

In the absence of population studies on the current malaria situation in the region, it is hard to measure any change that may be occurring now or later, for the lack of baseline data for comparison. Emerging evidence shows that most highlands of Tanzania are experiencing a worsening malaria situation in terms of increasing disease transmission (Cox et al., 1999; Bødker et al., 2003; Mboera et al., 2005). In addition, Mbeya regional health statistics showed annual morbidity attributable to malaria as high as $36 \%$ in

*To whom correspondence should be addressed. E-mail: maeggabta@africaonline.com 
1999 and 2000. In the same period, malaria mortality was $26 \%$ in 1999 and $34 \%$ in 2000. In 2001, malaria mortality was reported as alarming, at $35 \%$ of total deaths.

In the past five decades, considerable work has been done on malaria epidemiology and control in Tanzania, mostly in the northeastern and southeastern parts of the country (Mnzava, 1991; Lyimo, 1993). However, there is very scanty recent work on malaria from the southern highlands zone, which include Iringa, Ruvuma, Mbeya and Rukwa Regions (altitude range $=480$ to $3000 \mathrm{~m}$ ). With the increase in number of cases and death due to malaria reported in health facilities in Mbeya and Iringa Regions (Maegga et al., 2005) it was considered important to carry out a study to determine malaria prevalence among outpatients attending health care facilities and among schoolchildren in Bulambya division of Ileje District in southwestern Tanzania.

\section{Materials and Methods}

\section{Study area}

Ileje District is largely mountainous, and extensively farmed, even on steep slopes with loose soil, often resulting in landslides. It is mostly deforested in areas near villages, and only Kabulu Forest Reserve remains, although this too constantly suffers from invasion by charcoal makers, firewood cutters and timber for home construction. According to the 2002 National Census, the district population is 110,194 composed of 51,786 males and 58,408 females. The majority of residents are peasants, with some especially the youth combining this with petty trading between and within villages. The predominant tribes are the Wandali and Walambya, both of which have strong filial affinity with residents of the adjacent districts of Chitipa and Karonga in Northern Malawi.

The district is served by one hospital at Isoko, two Health Centres and 22 dispensaries. This study was carried out in Bulambya division, which is mainly a high plateau (1000-1350m) with mountainous portions towards its eastern boundaries with the Bundali division. It is subdivided into 8 administrative wards, where the study villages and schools were selected.

\section{Study design}

Records of total number of outpatient attendance for all causes and those attributed to malaria during 1999 - 2002 were collected from 11 health facilities, including 2 Health Centres of Itumba and Ibaba; 9 dispensaries of Magereza, Ileje Day, Isongole, Ikumbilo, Msia, Mbebe, Bupigu, Itale and Mlale.
Annual morbidity attributable to malaria was calculated as percentage prevalence of total outpatient cases for that year. Except for two health centres where there were laboratory facilities, malaria cases were diagnosed by clinical symptoms and not supported by laboratory blood tests at the nine dispensaries.

A cross sectional survey for malaria parasite was carried out in 16 primary schools, where two schools were selected in each ward. Thick blood films were prepared from finger prick blood of schoolchildren. Blood films were stained using $10 \%$ freshly prepared Giemsa stain, washed, dried and examined under compound microscope for identification of malaria parasites. Pupils whose blood was found positive for malaria parasites were referred for treatment at the nearest health facility, with support of their head teachers.

Mosquitoes were collected from 10 houses of each of the eight wards of Bupigu, Isongole, Itumba, Chitete, Mbebe, Ndola, Itale and Ibaba. The former five wards are in the warmer and drier undulating plateaux area, whereas the later three wards are in the cooler and more humid upper part of the highlands towards the eastern boundaries of Bulambya division. Indoor resting mosquitoes were knocked down using commercial aerial spray and collected from white bed sheets spread on the floor. Mosquito identification was done using a dissection microscope, according to standard keys of Gillies \& De Meillon (1968).

\section{Results}

A total of 333,528 outpatients were registered at the health facilities in the study period and out of these, $30.2 \%$ of the cases were attributed to malaria. The annual mean malaria morbidity was 25,197 or $32.8 \%$ of total facility attendance. The highest mean malaria morbidity in the four-year period was $50.5 \%$ (range= $37.7-60.7 \%$ ) at Itumba. The lowest mean malaria morbidity was $22.3 \%$ (range $=11.5-27.2 \%$ ) recorded at Ibaba (Figure 1). The facilities in the higher altitudes $(>1350 \mathrm{~m})$ reported lower morbidity than those in the lower plateaus.

A total of 502 schoolchildren (age 11-13 years) was screened for malaria parasites. Mean malaria parasitaemia rate was $9.9 \%$, varying between locations (Table 1). The highest prevalence was observed at Ikumbilo (36.7\%) and Ilulu (34.8\%) in the plateau area. None of the examined pupils had malaria parasites in Bupigu, Ndola, Itale, Iwala, Ibaba, and Shuba. With the exception of Bupigu, the other five schools are in the high altitude zone. Bupigu village is located on steep hill slopes towards the highland zone. 


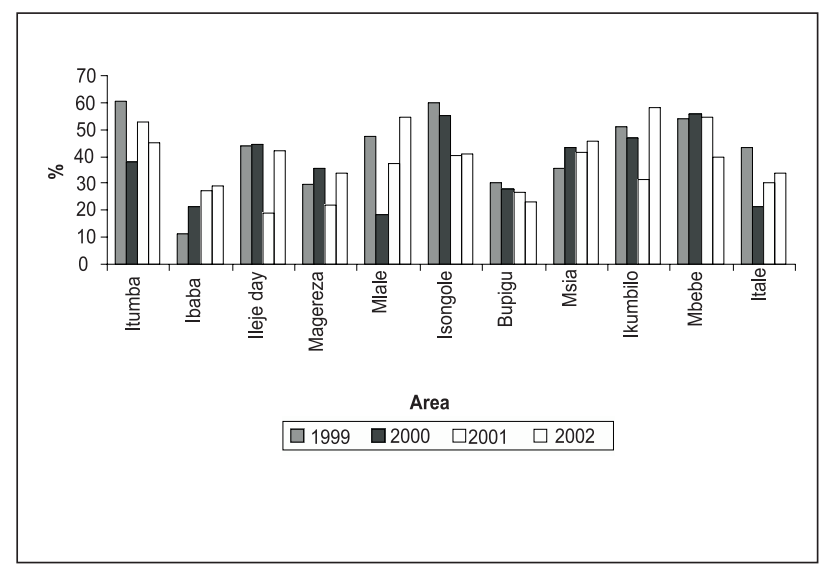

Figure 1: Malaria as a proportion of total outpatients in health facilities in Bulambya, 1999 -2002

A total of 1,185 female mosquitoes were collected indoors. The majority of the mosquitoes were culicines (Table 2). An. gambiae s.l. accounted for $17.3 \%$ $(\mathrm{N}=205)$ whereas An. funestus accounted for $18.1 \%$ $(\mathrm{N}=215)$ of the total mosquitoes caught. Female $A n$. gambiae and An. funestus were collected in relatively resting density per house for anopheline mosquitoes, varied considerably, with Mbebe leading with 21.4, Chitete 12.9, Isongole 3.2, Itumba 2.1, Bupigu 1.3, Shuba 0.6 and Ishenta 0.5 .

The mosquito population survey was done several weeks after the long rains had unexpectedly stopped, leaving the area fairly dry at the time. As a consequence, mosquito breeding sites were largely reduced in size and numbers at the time of survey, and therefore malaria transmission peak season may have been missed.

\section{Discussion}

The highlands of East Africa were regarded by colonial settlers as free from malaria infection (James, 1929; Matson, 1957; Clyde, 1967). Health facility based records showed that malaria is an important health problem in Bulambya division even in villages at high altitudes. This was substantiated by the malariometric survey, which revealed malaria parasitaemia prevalence in a number of villages in the study area.

Table 1: Prevalence of malaria parasitaemia in schoolchildren in Bulambya, May 2004

\begin{tabular}{|c|c|c|c|c|}
\hline Ward & School & No. examined & No. positive & Prevalence $\%$ \\
\hline \multirow[t]{2}{*}{ Mbebe } & Mbebe & 44 & 5 & 11.4 \\
\hline & Shinji & 41 & 3 & 7.3 \\
\hline \multirow[t]{2}{*}{ Chitete } & Chitete & 29 & 7 & 34.1 \\
\hline & Ikumbilo & 30 & 11 & 36.7 \\
\hline \multirow[t]{2}{*}{ Isongole } & Ikulu & 31 & 8 & 34.8 \\
\hline & Izuba & 30 & 9 & 30.0 \\
\hline \multirow[t]{2}{*}{ Bupigu } & Bupibu & 28 & 0 & 0.0 \\
\hline & Chabu & 21 & 1 & 4.8 \\
\hline \multirow[t]{2}{*}{ Itumba } & Itumba & 38 & 3 & 7.9 \\
\hline & Mlale & 30 & 2 & 6.7 \\
\hline \multirow[t]{2}{*}{ Ndola } & Ndola & 32 & 0 & 0.0 \\
\hline & Ishenta & 38 & 1 & 2.6 \\
\hline \multirow[t]{2}{*}{ Itale } & Itale & 29 & 0 & 0.0 \\
\hline & Iwala & 29 & 0 & 0.0 \\
\hline \multirow[t]{2}{*}{ Ibaba } & Ibaba & 29 & 0 & 0.0 \\
\hline & Shuba & 23 & 0 & 0.0 \\
\hline Total & & 502 & 50 & 9.9 \\
\hline
\end{tabular}

greater numbers in Mbebe, Isongole and Itumba wards. Large numbers of culicines were collected from Isongole followed by Itumba. These two are trading centres with urbanised settlements. The mean indoor
In recent years, malaria prevalence and incidence have been reported in a number of districts at high altitudes (Mboera et al., 2002, 2005; Kamugisha et al., 2005; Maegga et al., 2005).

Table 2: Female Anopheles mosquitoes caught in Bulambya

\begin{tabular}{llccc}
\hline Ward & Village & No. mosquitoes & An. gambiae & An. funestus \\
\hline Mbebe & Mbebe & 227 & 96 & 118 \\
Chitete & Chitete & 131 & 62 & 67 \\
Isongole & Isongole & 686 & 17 & 15 \\
Bupingu & Bupigu & 13 & 8 & 5 \\
Itumba & Itumba & 117 & 16 & 5 \\
Ndola & Ishenta & 5 & 2 & 3 \\
Itale & Iwala & 0 & 0 & 0 \\
Ibaba & Shuba & 6 & 4 & 2 \\
Total & & 1,185 & 205 & 215 \\
\hline
\end{tabular}


Our malariometric and health-facility data confirm significant surges in malaria in the southwestern highlands of Tanzania. In a recent study, Maegga et al. (2005) reported high number of malaria cases in ten hospitals in Iringa and Mbeya regions. During the last century, malaria has encroached into these highlands as a result of wide-scale population settlement (Mboera et al., 2002; Matson, 1957; Campbell, 1929). The reasons for the increase in malaria in the highlands are many, and may include frequent human population movements from the malaria endemic lowlands (Matola et al., 1987), climate change (Kilian et al., 1999; Odongo-Aginya et al., 2005), increased land use for agricultural extension and antimalarial drug resistance (Bødker $e t$ $a l ., 2000)$. The unstable and seasonal malaria transmission in such highland areas in Tanzania has resulted into frequent malaria epidemics (Mboera \& Kitua, 2001; Mboera, 2004).

The yearly magnitude of malaria problem in our study area is likely to be influenced by the amount and duration of rainfall, which creates favourable conditions for mosquito vector population build up. The malaria morbidity variations at each facility were independent of the other units, thus one facility in one year recorded a higher or lower proportion of malaria morbidity than the neighbouring facility whereas in the subsequent year, the picture could be vice versa. This is not surprising, considering the very complex malaria epidemiology, as influenced by the equally complex local relief features, and the combination of factors which together act in concert to strongly influence its dynamics of transmission. In addition, the accuracy and consistence of health information in any facility is dependent on adequately skilled and highly disciplined human power. It is therefore essential to acquire adequate knowledge of the local vector bionomics and epidemiology of malaria transmission in these highlands, through research, and establish firm and reliable database for future monitoring of the situation.

The generally low malaria prevalence at higher altitudes $(>1350 \mathrm{~m})$, where facility based records showed lower morbidity throughout the 4-year period is supported by the results of malariometric survey. Interestingly, it was also noted that, malaria morbidity levels at Ibaba, situated in high altitudes, showed an increasing trend each year, whereas the lower plateau facilities, although recording significantly higher morbidity levels, did not show such a steady increase or decline in the same period. Systematic population based study over time will be useful to confirm if indeed there was a tangible temporal increase in malaria morbidity.

The presence of indoor resting mosquitoes, both An. gambiae s.l. and An. funestus were evidence of the presence of known vectors species and local transmission. Furthermore, species identification of both An. gambiae complex and An. funestus group endemic in this area is an essential prerequisite before any control measure is considered, since different species elicit different sets of behaviours which must be taken into consideration while planning control options. It is therefore, recommended that more systematic, longitudinal research on malaria and its vectors be conducted in this area, especially documenting vector bionomics and parasite transmission at different altitude ranges, for the purpose of planning appropriate control and preventive measures under locally prevailing conditions.

\section{Acknowledgements}

We are very grateful to the District Council Authorities of Ileje and Divisional leadership of Bulambya, including all Ward Executive Officers for their support and enthusiasm. Our gratitude is also due to all clinical personnel in charge of the health facilities, as well as the school authorities at district and institutional level. Our special thanks go to the school children and communities who participated in the study. Thanks are also due to Dr. S. M. Magesa, Director, Amani Medical Research Centre, for facilitating the survey. Mr. E.Z. Sambu is thanked for his excellent technical assistance. This study received financial support from Health Research Users' Trust Fund of the Tanzanian Ministry of Health.

\section{References}

Bødker, R., Akida, J., Shayo, D., Kisinza, W., Msangeni, H.A., Pedersen, E.M. \& Lindsay, S.W. (2003) Relationship between altitude and intensity of malaria transmission in the Usambara Mountains, Tanzania. Journal of Medical Entomology 40, 706 - 717.

Campbell, J.M. (1929) Malaria in the Uasin Gishu and the Trans Nzoia. Kenya. East African Medical Journal 6, 32-43.

Clyde, D.F. (1967) Malaria in Tanzania. London: Oxford University Press

Cox, J., Craig, M., Le Suer, D. \& Sharp, B. (1999) Mapping Malaria Risk in the Highlands of Africa: MARA/HIMAL Technical Report, December 1999.pg 63-93.

Gillies, M.T. \& De Meillon, B. (1968) The Anophelinae of Africa South of the Sahara (Ethiopian zoogeographical region) $\left(2^{\text {nd }} E d\right.$.) Johannesburg: The South African Institute for Medical Research. 
James, S.P. (1929) Report on a Visit to Kenya and Uganda to Advise on Antimalarial Measures. London; His Majesty's Stationery Office.

Lyimo, E.O.K. (1993) The Bionomics of the Malaria Mosquito Anopheles gambiae sensu lato in Southeast Tanzania: Adult Size Variation and its Effect on Female Fecundity, Survival and Malaria Transmission. Ph.D. Thesis University of Wageningen, The Netherlands. Pp 142.

Kamugisha, M.L., Maxwell, C.A. \& Curtis, C.F. (2005) Characteristics of malaria among communities living in lowlands and highlands of Muheza District, north-east Tanzania. Tanzania Health Research Bulletin 7, 67-72.

Kilian, A., Langi, P., Talisuna, A. \& Kabagambe, G. (1999) Rainfall pattern, El Nino and malaria in Uganda. Transactions of the Royal Society of Tropical Medicine \& Hygiene 93, 22-23.

Maegga, B.T.A., Malley, K.D. \& Cox, J. (2005) The assessment of malaria situation in ten Voluntary Agency Hospitals in Iringa and Mbeya Regions, Southwest Tanzania. Tanzania Health Research Bulletin 7,000125-132.

Matola, Y.G., White, G.B. \& Magayuka, S.A. (1987) The changed pattern of malaria endemicity and transmission at Amani in the eastern Usambara Mountains, north-eastern Tanzania. Journal of Tropical Medicine \& Hygiene 90, 127-134.

Matson, A.T. (1957) The history of malaria in Nandi. East African Medical Journal 34, 431-441.

Mboera, L.E.G. (2004) Environmental and socioeconomic determinants of malaria epidemics in the highlands of Tanzania, Tanzania Health Research Bulletin 6, 11-17.

Mboera, L.E.G., Kamugisha, M.L., Malima, R.C., Mushi, A.K., Msuya, F.H., Masawe, T. \& Kitua, A.Y. (2002) Malaria prevalence and health seeking behaviour among communities of the lowlands and highlands of Gonja, Same District, north-eastern Tanzania. Tanzania Health Research Bulletin 4, 47-53.

Mboera, L.E.G. \& Kitua, A.Y. (2001) Malaria epidemics in Tanzania; An overview. African Journal of Health Sciences 8, 14-18.

Mboera, L.E.G., Malima, R.C., Mangesho, P.E., Senkoro, K.P. \& Mwingira, V. (2005) Malaria among the pastoral communities of the Ngorongoro Crater area, northern Tanzania. Tanzania Health Research Bulletin 7, 79-87.

Minja, S.H. \& Matola, Y. G. (1982) Kyela district: malaria in the human population. Annual Report of the National Institute for Medical Research 1, 14.

Mnzava, A.P. (1991) Epidemiology and Control of Malaria Transmission by Residual House Spraying with DDT and Lambdacyhalothrin in two Populations of the Anopheles gambiae complex in Tanga Region, Tanzania. Basel, Ph.D. Thesis pp 169.

Odongo-Aginya, E., Ssegwanyi, G., Kategere, P. \& Vuzi, P.C. (2005) Relationship between malaria infection intensity and rainfall pattern in Entebbe, Uganda. African Health Sciences 5, 238-245.

WHO (1993) A Global Strategy for Malaria Control. World Health Organization, Geneva, Switzerland. 